\title{
Modelling the Severity of Plastic Shrinkage in Cementitious Materials
}

\author{
Faez Sayahi \\ faez.sayahi@1tu.se \\ Luleå University of Technology, Luleå, Sweden \\ Mats Emborg \\ mats.emborg@1tu.se \\ Luleå University of Technology, Luleå, Sweden \\ Hans Hedlund \\ hans.hedlund@1tu.se \\ Luleå University of Technology, Luleå, Sweden \\ Andrzej Cwirzen \\ Andrzej.cwirzen@1tu.se \\ Luleå University of Technology, Luleå, Sweden \\ Marcin Stelmarczyk \\ marcin.stelmarczyk@1tu.se \\ Luleå University of Technology, Luleå, Sweden
}

\begin{abstract}
Plastic shrinkage cracking in cement-based materials occurs between the mixing and the final setting of the mixture, where rapid evaporation of the mixed water is the main cause behind the phenomenon. The induced cracks may impair the durability and sustainability of the structure by facilitating ingress of harmful materials into the concrete bulk. In this paper a new model for estimating the cracking severity of plastic cementitious materials is presented based on the mixture's initial setting time and the amount of the pore liquid evaporated from within the concrete mass. Results of experiments performed by the authors in another study, in addition to results of tests performed by other researchers are used to control the validity of the model. It is concluded that the model can anticipate the cracking severity of plastic concretes with good precision. The new method can provide practical tools for designers and contractors to predict and compare the cracking risk of the concretes prior to casting.
\end{abstract}

Keywords: Plastic shrinkage cracking; Initial setting; Evaporation; Bleeding; Modelling

\section{INTRODUCTION}

Plastic shrinkage cracking in concrete occurs shortly after casting and before the final setting of the mixture, while the concrete still has low tensile strain capacity (Lerch, 1957; Ravina \& Shalon, 1968). The aesthetics, durability and serviceability of a structure may be dramatically impaired, as cracks provide passages for harmful materials to reach the concrete interior and cause long-term damage. The physical aspect of plastic shrinkage is manifested in evaporation of the capillary water and the consequent build-up of a hydraulic pressure, also known as capillary pressure inside the pore network (Powers, 1968).

After placing the concrete in the mold, its solid particles settle under gravitational forces, making the pore liquid to move upwards to the surface, i.e. bleeding regime (Lura 
et al., 2007). This accumulated surface water eventually evaporates, after which menisci form inside the concrete's pores, i.e. drying regime (Lura et al., 2007). At this point, a negative capillary pressure builds-up inside the concrete bulk, which applies tensile forces on the solid particles. Cracks may form once the accumulated tensile stresses surpass the relatively low tensile strength of the fresh concrete (Powers, 1968).

Capillary pressure build-up in the pore network and accordingly the evolution of tensile stresses inside the concrete bulk depend on several parameters, such as $\mathrm{w} / \mathrm{c}$ ratio and permeability. On the other hand, development of the tensile strength is consistent with the hydration rate, which depends on the binder type and $\mathrm{w} / \mathrm{c}$ ratio.

The mechanism of plastic shrinkage in the drying state of cementitious materials have been investigated in a number of studies, e.g. (Powers, 1968; Dao et al., 2010; Wittmann, 1976; Radocea, 1992) based on which several models were developed. However, it seems that these models sometimes cannot explain some particular cases of plastic shrinkage cracking, where for example, concretes exhibit higher cracking tendency despite of their lower evaporation compared to other mixtures.

This paper presents a new model to predict the severity of plastic shrinkage cracking in cement-based materials, based on the concrete's tensile stress-strength ratio, which in turn is defined as function of the water evaporated from inside the concrete pore network, drying time, and the initial setting time. The model predicts and/or compares the cracking risk of concretes prior to placement, and identifies the one with the least cracking tendency.

\section{MODEL DERIVATION}

Drying time, i.e. when all the bleed water accumulated at the surface evaporates (Kwak \& Ha, 2006) is the beginning of a period during which the potential for plastic shrinkage cracking gradually increases. This is when the tensile stresses start to develop inside the concrete bulk, brought by the beginning of the capillary pressure build-up (Boshoff \& Combrinck, 2013). Hence, the longer critical period, $t_{c r}$, i.e. the period between the drying time and the mixtures initial set, see Fig. 1, the higher the cracking potential and vice versa (Sayahi et al., 2019). The critical period is defined as:

$$
\begin{aligned}
& t_{c r=} t_{i n i}-t_{d} \\
& \text { and } \\
& t=t_{d} \text { when } \frac{E}{B}=1
\end{aligned}
$$

Where $t_{c r}$ is the critical period (min), $t$ is time (min), $t_{i n i}$ is the initial setting time (min), $t_{d}$ is the drying time (min), $E$ is the evaporation $\left(\mathrm{kg} / \mathrm{m}^{2}\right)$, and $B$ is the bleeding $\left(\mathrm{kg} / \mathrm{m}^{2}\right)$. 


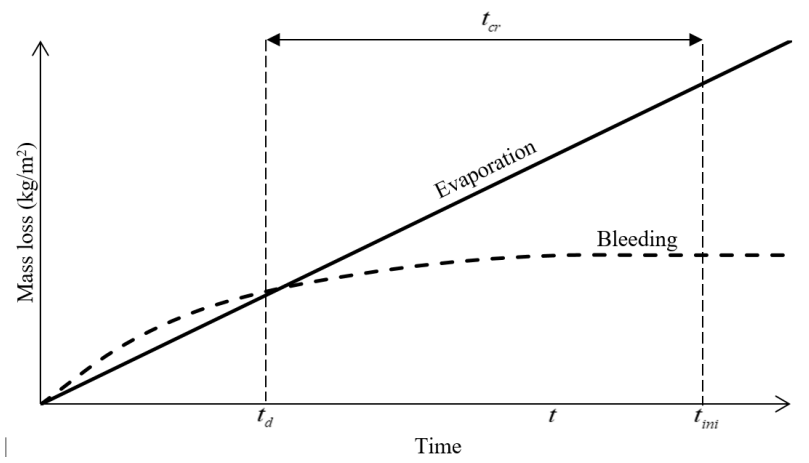

Figure 1: Drying time and critical period, from (Sayahi et al., 2019)

Assuming that cracking tendency of plastic cement-based materials increases with a higher rate of capillary pressure build-up, alongside delayed initial set and longer critical period, the following similarity is proposed:

$$
C_{s} \sim t_{i n i} \times \frac{d P}{d t} \times\left(t_{i n i}-t_{d}\right)
$$

Where $C_{s}$ is the severity of plastic shrinkage cracking $\left(\mathrm{kg} \cdot \mathrm{h} / \mathrm{m}^{2}\right)$, and $P$ is the capillary pressure $(\mathrm{Pa})$.

If the geometry of a pore is assumed constant, the rate of capillary pressure build-up will be a function of time, evaporation, $W_{e}$ (the volume between curves 1 and 3 in Fig. 2 ), and the upwards transferred water, $W_{b}$ (the water volume between curves 2 and 3 in Fig. 2) (Radocea, 1992; Sayahi et al., 2019).

$$
\frac{d P}{d t}=f\left(W_{e}, W_{b}, t\right)
$$

Where $W_{e}$ is the total amount of the evaporated water in a single pore $\left(\mathrm{kg} / \mathrm{m}^{2}\right)$, and $W_{b}$ is the total amount of the upwards transferred water in a single pore $\left(\mathrm{kg} / \mathrm{m}^{2}\right)$.

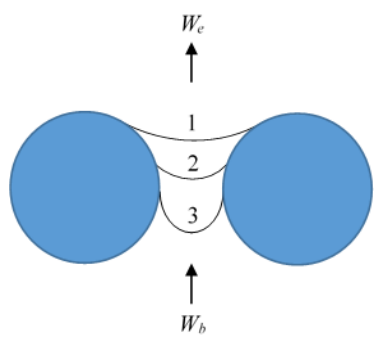

Figure 2: Water evaporation in a pore, based on (Radocea, 1992)

In such a case, according to (Radocea, 1992):

$$
\frac{d P}{d t} \frac{d W_{r}}{d P_{r}}=\frac{d W_{e}}{d t}-\frac{d W_{b}}{d t}
$$

Where $W_{r}$ is the amount of the evaporated water in a sample with no $W_{b}$, and $P_{r}$ is the 
pressure in a sample with no $W_{b}$.

In Eq.5, $d W_{r} / d P_{r}$, is the tangent to the PW'-curve in Fig. 3, which is always positive, until the air-entry point is reached. Hence, the change of the pressure rate is similar to the way that the difference between the rates of $W_{e}$ and $W_{b}$ differs, which in turn is similar to the change of the pore liquid evaporation rate from within the concrete mass.

$$
\frac{d P}{d t} \sim\left\lceil\frac{d W_{e}}{d t}-\frac{d W_{b}}{d t}\right\rceil \sim \frac{d W_{p}}{d t}
$$

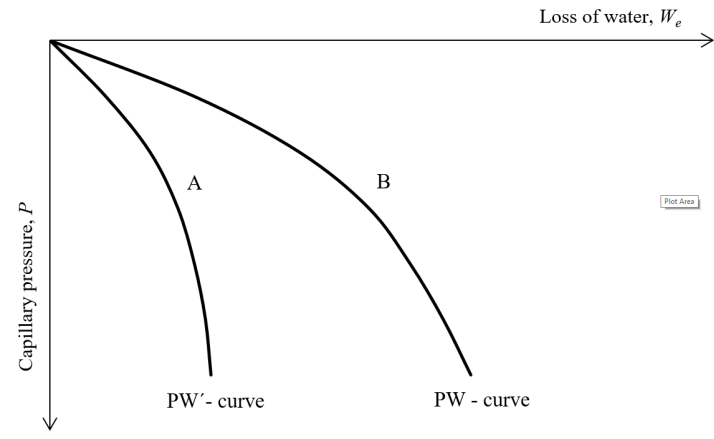

Figure 3: Capillary pressure build-up in A) a saturated sample where $W_{b}=0$ and B) a saturated sample where $\quad W_{b}>0$, based on (Radocea, 1992).

Where $W_{p}$ is the amount of the capillary water evaporated from inside the concrete pore network $\left(\mathrm{kg} / \mathrm{m}^{2}\right)$. Accordingly, the following model is proposed for anticipating the cracking severity in plastic cement-based materials:

$$
C_{s}=t_{i n i} \times \frac{d W_{p}}{d t} \times\left(t_{i n i}-t_{d}\right)
$$

According to Boshoff and Combrinck (2013):

$$
W_{p}(t)=E(t)-B(t) \quad, \quad t \geq t_{d}
$$

Where $W_{p}(t)$ is the amount of the water evaporated from inside the pore network at time $t\left(\mathrm{~kg} / \mathrm{m}^{2}\right)$, see Fig. 4, $E(t)$ is the total evaporation at time $t\left(\mathrm{~kg} / \mathrm{m}^{2}\right)$, and $B(t)$ is the total bleeding at time $t\left(\mathrm{~kg} / \mathrm{m}^{2}\right)$.

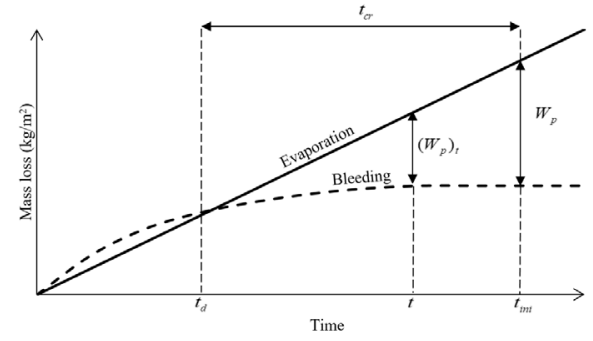

Figure 4: Definition of $W_{p}(t)$, from (Sayahi et al., 2019) 
In eq. (7), the product of the multiplication of $\left(d W_{p} / d t\right)$ and $\left(t_{i n i}-t_{d}\right)$, is the total amount of the water evaporated from inside the pore system at the initial set. Thus:

$$
\begin{aligned}
& C_{s}=W_{p} \times t_{i n i} \quad, \quad t=t_{i n i} \\
& \text { or } \\
& C_{s}=[E(t)-B(t)] \times t_{i n i} \quad, \quad t=t_{i n i}
\end{aligned}
$$

Using the new model, it is possible to explain the difference between the cracking tendency of mixtures with equal amount of evaporation. By multiplying the total $W_{p}$ in $t_{i n i}$, the new model emphasizes on the role of the initial setting time in the cracking tendency of plastic cementitious materials. Accordingly, in Fig. 5, the second concrete with the delayed initial setting is more prone to plastic shrinkage cracking in comparison to the first concrete with the faster setting.

To estimate the evaporation rate Uno's formula (Uno, 1998) or the ACI nomograph (ACI 305R, 1999) can be used. Bleeding, on the other hand, may be predicted according to models proposed by several researchers (Kwak \& Ha, 2006; Josserand et al., 2006; Morris \& Dux, 2010).

The initial setting time may be experimentally determined before the placement by using Vicat needle apparatus or ultrasonic waves (Carette \& Staquet, 2015), or after casting by determining the inflection point of the internal temperature curve.

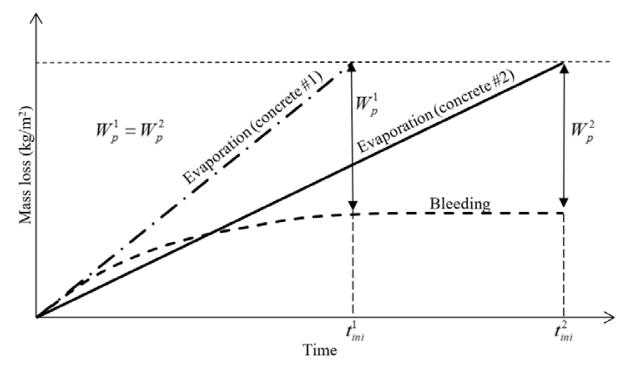

Figure 5: Cracking potential of concretes with equal $W_{p}$, but different initial setting times, from (Sayahi et al., 2019)

One limitation of the proposed model is that the restrain degree of the concrete is assumed constant for all the specimens. In addition, the effect of hydration, i.e. autogenous shrinkage, is neglected and it is assumed that the cracking occurs only due to the drying of the mixed water.

\section{MODEL VERIFICATION}

Some experimental data presented by the authors in (Sayahi et al., 2016) are used to verify the practicality of the model. The tests were performed using self-compacting concretes (SCC) in a mold manufactured according to the NORDTEST-method (Johansen \& Dahl, 1993). The bleeding was measured according to (EN 480-4, 2005). Fig. 6 plots the calculated $C_{s}$ versus the measured average final crack areas, which seem directly proportional. The only mixture that falls way out of this range has a w/c ratio of 0.55 . This particular mixture is still in the optimum crack reducing $\mathrm{w} / \mathrm{c}$ ratio range, defined by (Sayahi, 2019), i.e. $0.45<\mathrm{w} / \mathrm{c}<0.55$, and thus, does not affect the cracking tendency. 


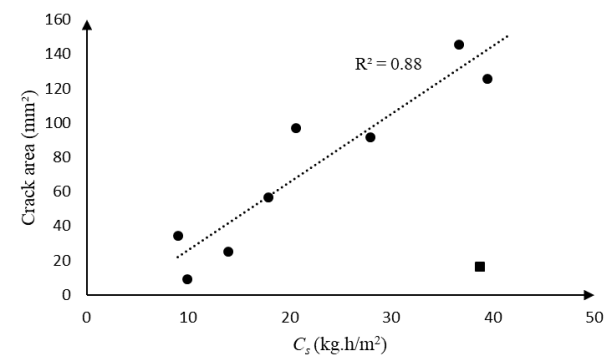

Figure 6: Cracking severity versus the measured average crack area, according to the new model, from (Sayahi et al., 2019)

Ghourchian et al. (2018) studied the influence of different Portland and blended cements on the cracking of plastic vibrated concrete (VC), during which they used an (ASTM C 1579-13, 2013) mold. By applying the model on the reported data by (Ghourchian et al., 2018), a linear correlation between the crack area and $C_{s}$ was detected, see Fig. 7. Thus, it was concluded that the model is applicable for both SCC and VC.

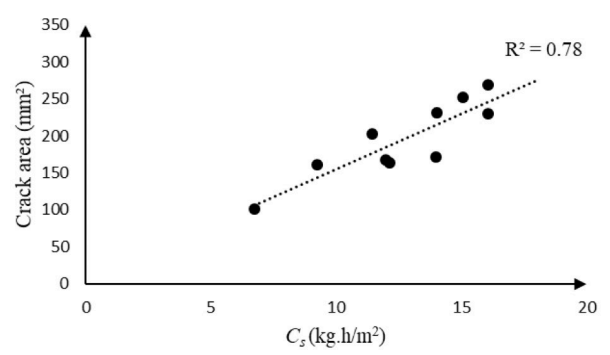

Figure 7: Cracking severity versus the measured average crack area, according to the new model and based on the data reported by (Ghourchian et al., 2018) from (Sayahi et al., 2019)

Maritz (2012) investigated the plastic shrinkage cracking of VC by focusing on evaporation and bleeding. He also used a mold manufactured according to (ASTM C $1579,2013)$. The quantified crack areas are plotted in Fig. 8 versus the calculated $C_{s}$.

The difference in the values of the measured crack areas, in Fig. 6 to Fig. 8, is caused by the variation of the restrain degree, since different molds were used in the above mentioned studies. Thus, it should be remarked that the new model is only applicable on a group of equally retrained specimens.

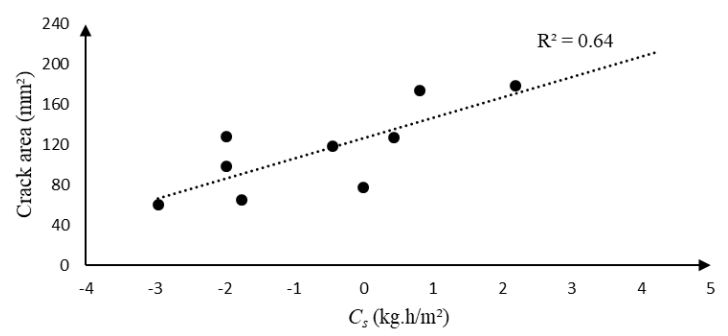

Figure 8: Cracking severity versus the measured average crack area, according to the new model and based on the data reported by (Maritz, 2012) from (Sayahi et al., 2019) 
The negative $C_{s}$ values in Fig. 8 mean higher bleeding compared to evaporation at the initial setting time. In such a case, the cracking may be attributed to initial plastic settlement of the vertically restrained specimens (Boshoff \& Combrinck, 2013).

Moreover, by comparing the value of $C_{s}$ in SCC (Fig. 6) to that of VC (Fig. 7 and Fig. 8), it can be seen that $C_{s}$ depends also on the concrete type. SCC has relatively lower bleeding capacity compared to $\mathrm{VC}$, based on which the observed dependency of $C_{s}$ may be explained. Accordingly, the new model gives higher values of $C_{s}$ for SCC in comparison to $\mathrm{VC}$, which confirms that mixtures of high cement content are more susceptible to plastic shrinkage cracking.

It ought to be mentioned here that the model is a simple method to estimate the cracking severity, in which some parameters such as the effect of admixtures are not included. Thus, more experiments are needed to develop a more comprehensive version of the model.

\section{CONCLUSION}

The new model may estimate the cracking severity in plastic cementitious materials, based on the amount of the water evaporated from within the pore network and the initial set of the mixture. Accordingly, the following concluding remarks can be made:

- The model predicts the severity of plastic shrinkage cracking in cementitious materials, even before placement.

- The cracking severity in plastic cement-based materials is directly proportional to the product of the amount of the water evaporated from within the pore system, and the initial setting time.

- The model works regardless of the concrete type, i.e. SCC or VC.

- The model can only estimate the cracking severity of equally restrained elements.

- The severity of plastic shrinkage cracking may be reduced by lowering the evaporation-bleeding ratio and/or accelerating the mixtures initial set.

\section{ACKNOWLEDGMENT}

The authors appreciate the financial support provided by the Development Fund of the Swedish Construction Industry, SBUF.

\section{REFERENCES}

ACI 305R-99 (1999). Hot Weather Concreting. Manual of Concrete Practice. Farmington Hills: American Concrete Institute.

ASTM C1579-13 (2013). Standard Test Method for Evaluating Plastic Shrinkage Cracking of Restrained Fiber Reinforced Concrete (Using a Steel Form Insert); ASTM International, West Conshohocken, PA.

Boshoff, W. P. \& Combrinck R. (2013). Modelling the severity of plastic shrinkage cracking in concrete. Cement and Concrete Research, 48, pp. 34-39.

Carette, J. \& Staquet, S. (2015). Monitoring the setting process of mortars by ultrasonic P and S-wave transmission velocity measurement, Const. Build. Mater., 94, 196-208.

Dao V., Dux, P., Morris, P. \& O'Moore, L. (2010). Plastic shrinkage cracking of concrete. 
Australian Journal of Structural Engineering. Vol. 10, No. 3, pp. 207-214.

EN 480-4: (2005). Admixtures for Concrete, Mortar and Grout. Test Methods, Determination of bleeding of concrete, BSI.

Josserand, L., Coussy, O. \& de, Larrard F. (2006). Bleeding of concrete as an ageing consolidation process. Cem. Concr. Res., 36 1603-1608.

Johansen, R. \& Dahl, P. (1993). Control of plastic shrinkage of cement. Proceedings of the 18th Conference on Our World in Concrete and Structures. Singapore, 1993.

Lerch, W. (1957). Plastic shrinkage. ACI Journal, 53(8): 797-802.

Lura, P., Pease, B., Mazzotta, G. B., Rajabipour, F. \& Weiss, J. (2007). Influence of shrinkagereducing admixtures on development of plastic shrinkage cracks. ACI Materials Journal, Vol. 104(2).

Morris, P. H. \& Dux, P. F. (2010). Analytical solutions for bleeding of concrete due to consolidation. Cem. Concr. Res., 40 1531-1540.

Powers, T. C. (1968). Properties of Fresh Concrete, p. 301, John Wiley and Sons, Inc., New York.

Ravina, D. \& Shalon, R. (1968). Plastic shrinkage cracking. ACI Journal, 65(4): 282-291.

Radocea, A. (1992). A study on the mechanism of plastic shrinkage of cement-based materials. Chalmers University of Technology.

Sayahi, F. (2019). Plastic Shrinkage Cracking in Concrete: Mitigation and Modelling. (Doctoral thesis). Luleå University of Technology, 2019.

Sayahi, F., Emborg, M., Hedlund, H., Cwirzen, A. \& Stelmarczyk, M. (2019). The severity of plastic shrinkage cracking in concrete: A new model. Magazine of Concrete Research. https:// doi.org/10.1680/jmacr.19.00279.

Sayahi, F., Emborg, M., Hedlund, H. \& Löfgren, L. (2016). Plastic shrinkage cracking in selfcompacting concrete: A parametric study. International RILEM conference on Materials, Systems and Structures in Civil Engineering, MSSCE 2016, pp. 609-619.

Uno, P. J. (1998). Plastic shrinkage cracking and evaporation formulas. ACI Mater Journal, Vol. 95, pp. 365-375.

Wittmann, F. H. (1976). On the action of capillary pressure in fresh concrete. Cem. Concr. Res. 6, 49-56. 